\title{
Sex chromosome evolution in moths and butterflies
}

\author{
Ken Sahara • Atsuo Yoshido $\cdot$ Walther Traut
}

Published online: 21 December 2011

(C) Springer Science+Business Media B.V. 2011

\begin{abstract}
Lepidoptera, i.e. moths and butterflies, have a female heterogametic sex chromosome system, with most females having a WZ constitution while males are ZZ. Besides this predominant WZ/ZZ system, Z/ZZ, $\mathrm{WZ}_{1} \mathrm{Z}_{2} / \mathrm{Z}_{1} \mathrm{Z}_{1} \mathrm{Z}_{2} \mathrm{Z}_{2}$ and $\mathrm{W}_{1} \mathrm{~W}_{2} \mathrm{Z} / \mathrm{ZZ}$ systems also occur. Sex is determined by an unknown W-linked gene or genes in Bombyx mori, but by dosage-dependent and equally unknown Z-linked genes in all Z/ZZ species. The female heterogametic sex chromosome system has been conserved for at least $180 \mathrm{MY}$ in the phylogenetic branch that combines Lepidoptera and Trichoptera. The $\mathrm{W}$ chromosome, which is present in most lepidopteran species, was incorporated in the sex chromosome system much later, about 90-100 MY ago. The Z chromosomes are highly conserved among Lepidoptera, much like the $\mathrm{Z}$ in birds or the $\mathrm{X}$ in mammals. The $\mathrm{W}$, on the other hand, is evolving rapidly. It is crammed with repetitive elements which appear to have a high turnover
\end{abstract}

Responsible Editors: Tariq Ezaz and Jennifer Graves.

K. Sahara $(\bowtie) \cdot$ A. Yoshido

Laboratory of Applied Molecular Entomology,

Research Faculty of Agriculture, Hokkaido University,

N9, W9, Kita-ku,

Sapporo 060-8589, Japan

e-mail: sahara@abs.agr.hokudai.ac.jp

W. Traut

Institut für Biologie, Zentrum für medizinische

Struktur- und Zellbiologie, Universität Lübeck,

Ratzeburger Allee 160,

23538 Lübeck, Germany rate but poor in or even devoid of protein-coding genes. It has frequently undergone fusion with autosomes or sporadically lost altogether.

Keywords BAC-FISH · conserved synteny · holokinetic chromosomes · sex determination . $\mathrm{W}$ chromosome $\cdot \mathrm{Z}$ chromosome

\begin{tabular}{|c|c|}
\hline \multicolumn{2}{|c|}{ Abbreviations } \\
\hline BAC-FISH & $\begin{array}{l}\text { FISH using bacterial artificial } \\
\text { chromosomes, as probes }\end{array}$ \\
\hline $\mathrm{CGH}$ & Comparative genomic hybridisation \\
\hline FISH & Fluorescence in situ hybridisation \\
\hline GISH & Genomic in situ hybridisation \\
\hline MY & Million years \\
\hline Zoo-FISH & $\begin{array}{l}\text { FISH using probes from one } \\
\text { species on other species }\end{array}$ \\
\hline
\end{tabular}

\section{Introduction}

Sex chromosomes provide the primary signal in the sexdetermining pathway and at the same time ensure a balanced sex ratio among offspring. Apart from their function, sex chromosomes are often the most conspicuous elements in a chromosome complement in terms of size, form, heterochromatinisation and behaviour in meiosis. This concerns especially the $\mathrm{Y}$ chromosome in XY systems and the $\mathrm{W}$ chromosome in WZ systems and led observation of spermatogenesis in the red 
firebug, Pyrrhocoris apterus, to the discovery of sex chromosomes in the early days of cytogenetics (Henking 1891). There has been a continuous interest in them since that time.

Sex chromosome systems have evolved independently many times in plants and animals. Some sex chromosome systems appear to be well conserved and have already had a long lifetime, e.g. those of mammals or birds among vertebrates. Others are more short-lived. Quite recently, the common house fly, Musca domestica, replaced its old XY system in many populations worldwide for new ones based on former autosomes (Franco et al. 1982). An extreme case is the fly Megaselia scalaris where replacement of the sex chromosome system by non-homologous new ones can be observed even under laboratory conditions (Traut 2010).

Once a chromosome pair has acquired the sexdetermining function, it appears to follow a universal evolutionary pathway that leads to crossover suppression and subsequent molecular differentiation, even visible cytogenetic differences between X and Y, or W and Z, and eventually loss of the $\mathrm{Y}$ or $\mathrm{W}$, given sufficient evolutionary time (for review, see Charlesworth et al. 2005).

We present here an ancient female heterogametic system where we can follow birth and decline of a $\mathrm{W}$ chromosome: the lepidopteran sex chromosome system. The insect order Lepidoptera, which contains moths and butterflies, is species-rich, comprises 160,000 described species and an estimated total number of half a million (Kristensen et al. 2007). Among them are species of commercial value and many pest insects. Lepidoptera, hence, offer a rich supply of material to study evolutionary pathways.

\section{Identification of sex chromosomes in Lepidoptera}

Chromosome numbers are known for more than 1,000 species of Lepidoptera (Robinson 1971), mostly from counting them in the easily accessible male meiotic metaphases. But only in a very limited number of species the sex chromosome constitution has been uncovered. This is because male meiotic metaphases are inadequate for species with female heterogamety. Mitotic chromosomes in Lepidoptera, on the other hand, are numerous (modal number $2 n=60-62$ ), small and without any landmarks, such as localised centromeres, chromosome bands or obvious heterochromatic segments, and, hence, are rather difficult objects for chromosome study (Fig. 1a). Female meiotic
Fig. 1 Identification of $\mathrm{W}$ chromosomes by FISH. a-c Comparative genomic hybridisation reveals the $\mathrm{W}$ chromosome of the tobacco horn worm, Manduca sexta. Female mitotic metaphase stained with DAPI (a). Female (green) and male (red) whole genomic probes highlight the W chromosome (b, c). d Genomic in situ hybridisation (GISH) applied to a female pachytene complement of Orgyia recens. Female genomic probe (red) paints the $\mathrm{W}$ thread of the WZ bivalent. Bar, $10 \mu \mathrm{m}$
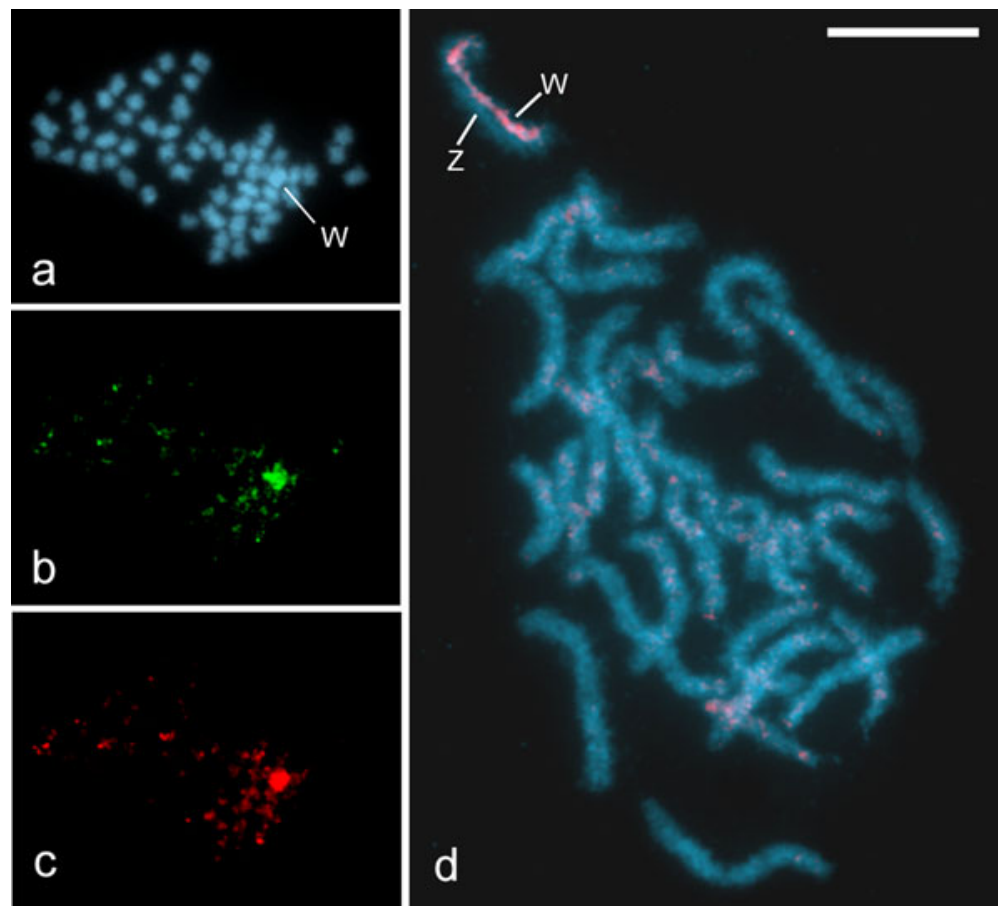
pachytene chromosomes proved to be considerably better for that purpose, they are longer and, having an achiasmatic meiosis, the homologues remain synapsed in a pachytene-like stage until metaphase I. The sex chromosome constitution of a number of lepidopteran species was revealed by analysing the pachytene complement. The heterochromatinised $\mathrm{W}$ thread in the WZ bivalent was thereby used as the cytogenetic marker for identification of the sex chromosome bivalent (Traut and Rathjens 1973; Traut and Marec 1997).

More recently, various fluorescence in situ hybridisation (FISH) techniques solved the problem of recognising the sex chromosomes. Comparative genomic hybridisation ( $\mathrm{CGH}$ ) was found to be generally applicable for identifying differentiated sex chromosomes, independent of any morphological markers (Fig. 1a-c; Traut et al. 1999). The simpler genomic in situ hybridisation (GISH) can also highlight sex chromosomes (Fig. 1d). Using GISH, Yoshido et al. (2006) analysed the sex chromosome constitution in 15 species of Lepidoptera. Even single W-derived bacterial artificial chromosomes (BACs) label the $\mathrm{W}$ chromosome along most of its length in Bombyx mori (FISH using BACs, as probes (BAC-FISH); Sahara et al. 2003b). FISH using probes from microdissected $\mathrm{W}$ chromosomes provide another generally applicable method to paint the W chromosome (Fuková et al. 2007; Vítková et al. 2007). The complex sex chromosome multivalents were still a tough problem until Yoshido et al. (2005) introduced telomere FISH combined with GISH to delineate chromosomes in pachytene sex chromosome multivalents (Fig. 2).

\section{Origin of the lepidopteran sex chromosome system}

Lepidoptera and the sister group Trichoptera stand out among insects as the only clade having a female heterogametic sex chromosome system (besides other characters in common). Female heterogamety, therefore, must have arisen in a common ancestor of the two insect orders, more than $180 \mathrm{MY}$ ago (the oldest dated fossils are from 180 to $190 \mathrm{MY}$ ago, Kristensen and Skalski 1999; Grimaldi and Engel 2005). All trichopteran species so far investigated (Marec and Novák 1998; Lukhtanov 2000) as well as basal lepidopteran families (Marec et al. 2010) have a Z/ZZ sex chromosome system. The W chromosome, which is considered characteristic for Lepidoptera, only occurs in the more 'advanced' families (Fig. 3). In a phylogenetic survey, Traut and Marec (1996) and Lukhtanov (2000) determined the clade in which the $\mathrm{W}$ chromosome appeared. The $\mathrm{W}$ came into being at the common root of Ditrysia and Tischerioidea, $\sim 97 \mathrm{MY}$ ago (the earliest record of a ditrysian species, Kristensen and Skalski 1999). It is not known yet whether the W had originally been an autosome whose homologue was fused to the ancestral $\mathrm{Z}$ (Traut and Marec 1996) or a B chromosome which was incorporated in the sex chromosome system by acquiring pairing partnership with the $\mathrm{Z}$ chromosome (Lukhtanov 2000).

\section{Variations of the WZ theme}

In a recent compilation of known sex chromosome systems in Lepidoptera, the largest fraction, 18 of 38
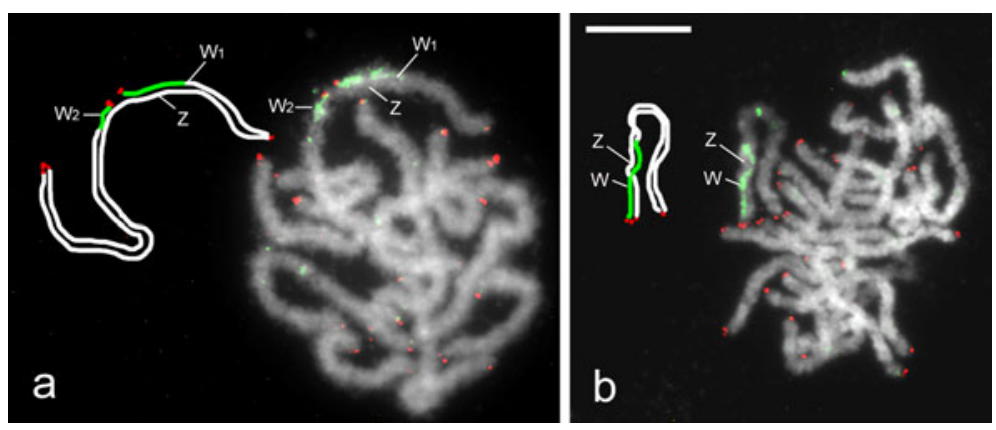

Fig. 2 A combination of GISH and telomere FISH delineates individual chromosomes in sex chromosome multivalents. A whole-genome female probe (green) detects the ancestral W segment and an insect telomere probe, (TTAGG) $n$ (red), the chromosome ends. a Sex chromosome trivalent in a female pachytene complement of Orgyia thyellina. The two W chromosomes, $\mathrm{W}_{1}$ and $\mathrm{W}_{2}$, are each composed of an ancestral $\mathrm{W}$ segment and a translocated autosomal segment. b Sex chromosome bivalent in a female pachytene complement of Orgyia antiqua. No telomeric signal was detected inside the sex chromosome bivalent. This indicates the presence of a single $\mathrm{W}$ with an ancestral $\mathrm{W}$ segment and a recently translocated presumably autosomal, segment 
Fig. 3 Phylogeny of the sex chromosome system in Lepidoptera and their sister group Trichoptera. The diagram presents super families arranged in a phylogenetic tree and the female sex chromosome constitution of species investigated (based on Marec et al. 2010 and references therein)

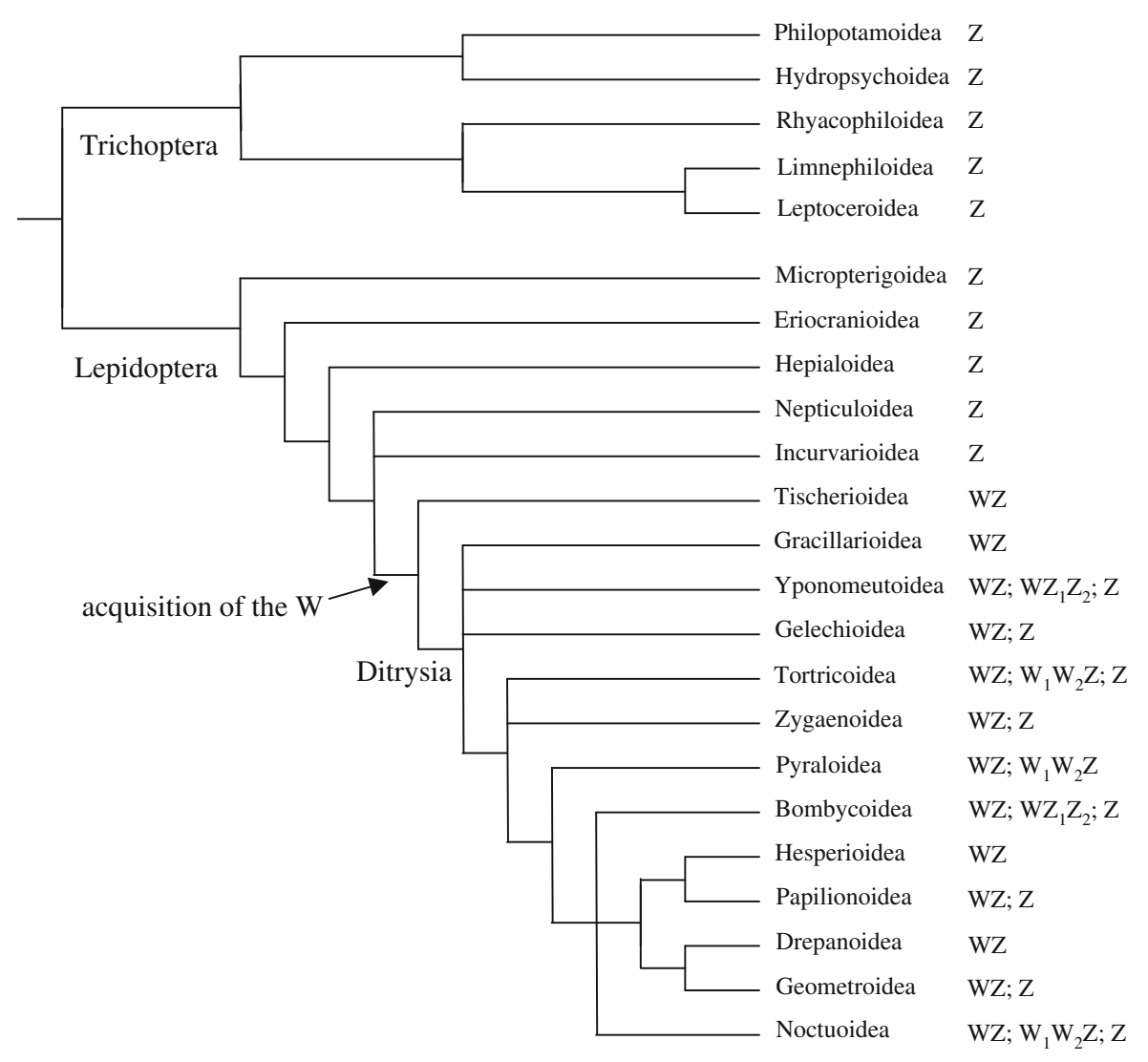

species, had a WZ/ZZ system (Traut et al. 2007). But they are certainly underrepresented in the compilation. $\mathrm{Z} / \mathrm{ZZ}$ systems, also called $\mathrm{Z} 0$ systems, $\mathrm{W}_{1} \mathrm{~W}_{2} \mathrm{Z} / \mathrm{ZZ}$ and $W Z_{1} Z_{2} / Z_{1} Z_{1} Z_{2} Z_{2}$ systems have also been discovered. While the $Z / Z Z$ constitution is the ancestral condition, present in all basal lineages of Lepidoptera, $\mathrm{Z} / \mathrm{ZZ}$ cases among advanced species are sporadic and considered due to secondary loss of the $\mathrm{W}$ chromosome. Multiple sex chromosomes, in contrast, owe their origin to chromosome fission or to chromosome fusion of the $\mathrm{W}$ or the $\mathrm{Z}$ with an autosome.

In favourable cases, the origin of a variant sex chromosome constitution can be uncovered and the participating chromosomes identified. In Samia cynthia, a wild silkmoth species, three chromosome races have been discovered in different populations (Yoshido et al. 2005). All three have different sex chromosome systems. The Vietnam population has a Z/ZZ system, the Sapporo population a $W Z / Z Z$ system and the Nagano population a $\mathrm{WZ}_{1} \mathrm{Z}_{2} / \mathrm{Z}_{1} \mathrm{Z}_{1} \mathrm{Z}_{2} \mathrm{Z}_{2}$ system. With FISH using fosmid and PCR-amplified genomic probes, the original constituents of the sex chromosome system were identified and traced back to homologous chromosomes of B. mori (Fig. 4; Yoshido et al. 2011a, b). In the $\mathrm{Z} / \mathrm{ZZ}$ race of the Vietnam population, the $\mathrm{Z}$ chromosome shows conserved synteny with the B. mori $\mathrm{Z}$ chromosome while the $\mathrm{W}$ was lost in the evolution of the population. The WZ/ZZ system of the Sapporo population is, in fact, a neo-W neo- $Z /$ neo- $Z$ neo- $Z$ system in which a homologue of chromosome 13 from the Vietnam population is fused to the ancestral $\mathrm{Z}$ chromosome, thus creating a neo- $Z$ chromosome. The other homologue appears to be fused to a remnant of the ancestral $\mathrm{W}$ chromosome, thereby forming a neo-W chromosome. The multiple sex chromosome system in the Nagano population, in turn, appears to be derived from the sex chromosome system found in the Sapporo population whereby the neo-W is seen to be fused with a chromosome 12 of the other populations. This produces a neo-W which pairs with a neo-Z like that from Sapporo, now a $Z_{1}$ and a free autosome 12 , which is now a $\mathrm{Z}_{2}$ chromosome.

Lepidopteran chromosomes are holokinetic with kinetochores covering most of the chromosome length 


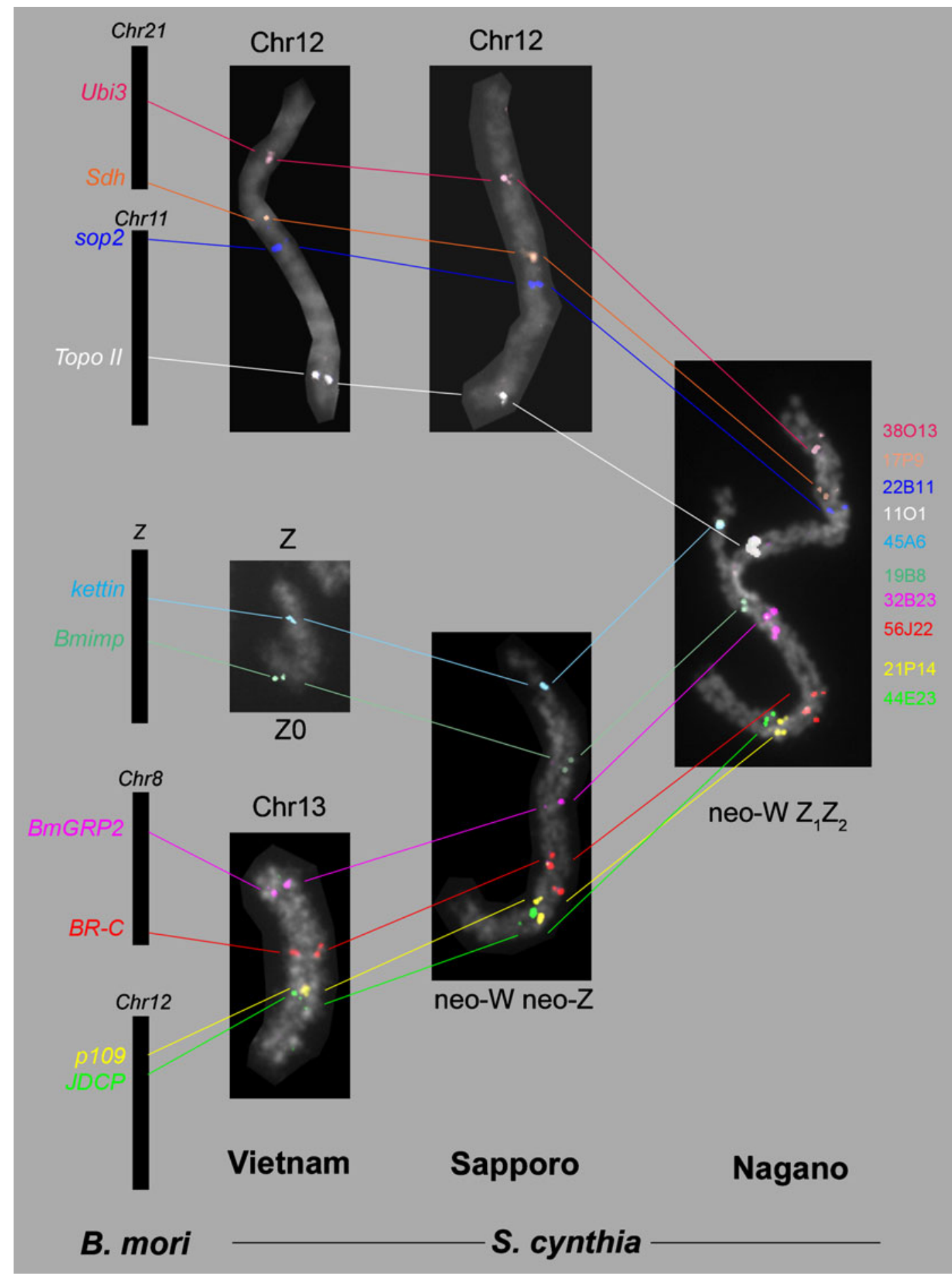

Fig. 4 Evolution of variant sex chromosome systems in $S$. cynthia. Fosmid-FISH detects conserved synteny between chromosomes of B. mori and S. cynthia and identifies the components of the sex chromosome univalent, bivalent and trivalent of the Vietnam, Sapporo and Nagano populations (for details, see Yoshido et al. 2011a, b) 
(Wolf 1996). Fusions as well as fissions should be facilitated with this type of chromosome. Consistent with this expectation, stable $\mathrm{W}$ chromosome fragments and multiple sex chromosome systems have been produced experimentally by $\gamma$-ray mutagenesis, in the meal moth Ephestia kuehniella (Traut and Rathjens 1973; Rathjens 1974; Traut et al. 1986). Fusion of the W with an autosome was found in four independent cases, giving rise to strains which have now been cultured for more than three decades. The fusion events produced neo-W chromosomes which paired in meiosis with two partners, the original $Z$ chromosome and the former autosome. Formally, these are $\mathrm{WZ}_{1} \mathrm{Z}_{2} / \mathrm{Z}_{1} \mathrm{Z}_{1} \mathrm{Z}_{2} \mathrm{Z}_{2}$ sex chromosome systems and would be called thus if found in the field.

\section{Sex determination in Lepidoptera}

As noted, in female heterogametic systems like those of Lepidoptera, the primary signal in the sex-determining pathway is either a female-determining signal encoded in the $\mathrm{W}$ chromosome or a dosage-dependent maledetermining signal encoded in the $\mathrm{Z}$ chromosomes. Both variants occur among lepidopteran species, but their molecular basis has not yet been discovered.

In $B$. mori, the $\mathrm{W}$ chromosome has a strong femaledetermining activity. This has been known for a long time from the analysis of polyploids (Tazima 1964; Traut et al. 2007). Whenever an embryo possesses a W, it enters the female pathway, irrespective of the number of $Z$ chromosomes present in its genome. Absence of a $\mathrm{W}$ determines the male sex. The feminising function, Fem, has been localised to a small region of the $\mathrm{W}$ chromosome by deletion mapping (Abe et al. 2010). It has not yet, however, been associated with a specific gene or genes.

In Z/ZZ systems, on the other hand, sex is determined by the number of $Z$ chromosomes. Presence of a single $Z$ chromosome in the genome causes female development, whereas presence of two $\mathrm{Z}$ chromosomes results in male development. In the chicken, DMRT1 is considered a Z-counting mediator that triggers the sex-determining pathway (Smith et al. 2009). In Lepidoptera, however, dosage-dependent male-determining genes on the $\mathrm{Z}$ chromosome have not been identified. It is also unknown whether WZ/ZZ species other than $B$. mori possess a sex-determining mechanism with $\mathrm{Fem}$ localised in the $\mathrm{W}$ chromosome, or whether sex determination depends on a Z-counting mechanism like in $\mathrm{Z} / \mathrm{ZZ}$ species.

The subsequent steps of the sex-determining pathway are partially known, mainly from B. mori. Sex-lethal $(S x l)$, which forms the key switch in Drosophila, is conserved and present in $B$. mori, but $B m-S x l$ transcripts are not sex-specifically spliced and, therefore, $B m-S x l$ seems not to play a role in the sex-determining pathway (Niimi et al. 2006). In Hymenoptera, Coleoptera and non-drosophilid Diptera, transformer (tra) has taken over the role of a key switch and that of a memory of the sexual state of a cell. But tra has not been found in $B$. mori or any other lepidopteran species and probably plays no role in regulating the last step in the sexdetermining pathway: sex-specific splicing and expression of Bmdsx, the B. mori ortholog of Drosophila's doublesex $(d s x)$. Instead, the male-specific BmIMP (B. mori homologue of IGF-II mRNA binding protein) together with BmPSI (B. mori homologue of P-element somatic inhibitor) are known to regulate splicing of $B m d s x$ (Suzuki et al. 2010). Orthologs of $d s x$ with sexspecific splicing are known from all investigated insects and even from a crustacean, Daphnia magna (Kato et al. 2011). The sex-specific Bmdsx transcripts code for two protein isoforms, a female form, BmDSXF, and a male form, BmDSXM. These proteins regulate transcription of sex-specific genes, such as those for yolk proteins. Detailed accounts on sex determination in B. mori have been published recently by Abe et al. (2010) and Suzuki (2010).

\section{Constituents of the $\mathrm{W}$ chromosome}

Gene and sequence information on the lepidopteran W chromosome are rather scarce. The $\mathrm{W}$ chromosome has been exempted from the genome sequencing of $B$. mori because of the expected problems with the high density of repetitive elements. Classical meiotic recombination mapping cannot be applied to the $\mathrm{W}$ as it is present only in females and has no genetic exchange with its partner, the $\mathrm{Z}$ chromosome. However, manipulation of chromosomes, polyploidisation and induced translocations and deletions, allowed researchers to map Fem to a limited region of the B. mori $\mathrm{W}$ chromosome (see above). In $E$. kuehniella, a putative male-killing factor has been assigned to a translocated W segment (Marec et al. 2001).

FISH techniques like CGH and GISH have been applied to a number of species. They give some insight 
into the molecular composition of the W. The $\mathrm{W}$ stands out in these preparations as the most densely labelled chromosome (Fig. 1). The intense hybridisation signal indicates accumulation of repetitive DNA in the W. Using CGH, a conspicuous portion of the repetitive sequence was found to be W-specific in the wax moth, Galleria mellonella. The W of B. mori, however, is filled with repetitive sequences which are ubiquitous in the genome (Sahara et al. 2003a).

This general property, a $\mathrm{W}$ densely populated with repetitive elements, was confirmed by analysis of sequences derived from the W. All DNA fragments hitherto isolated from the $\mathrm{W}$ chromosome of $B$. mori contained retrotransposon sequence (Abe et al. 2010). DNA sequences isolated from the $\mathrm{W}$ chromosome of the codling moth, Cydia pomonella, by microdissection, were multicopy (with three exceptions), but only three out of 17 sequence motifs were confirmed retrotransposons (Fuková et al. 2007).

The sequence composition of the $\mathrm{W}$ appears to have a rather high turnover rate in evolution. FISH probes generated by microdissection from the $\mathrm{W}$ chromosomes of E. kuehniella, Cadra cautella, Plodia interpunctella and G. mellonella, all from the family Pyralidae, paint the $\mathrm{W}$ of the respective species in chromosome preparations. But when the E. kuehniella probe was cross hybridised to $\mathrm{W}$ chromosomes of the other species ('Zoo-FISH', Fig. 5), the hybridisation signals were rather patchy in C. cautella and P. interpunctella and scarce and dot-like or absent in G. mellonella (Vítková et al. 2007). So even in related species of the same family, the composition of the $\mathrm{W}$ has changed to an extent that it is no longer recognised by hybridisation.

\section{Constituents of the $\mathrm{Z}$ chromosome}

In contrast to the $\mathrm{W}$, the $\mathrm{Z}$ chromosome of $B$. mori was included in the whole-genome sequencing projects and the assembled sequence made accessible in public databases (The International Silkworm Genome Consortium 2008). The overall sequence composition of $Z$ is much like that of autosomes but unlike the composition of its partner $\mathrm{W}$. In contrast to the $\mathrm{W}$, the $\mathrm{Z}$ chromosome is rather conservative. The $\mathrm{Z}$ chromosomal gene content is conserved among Lepidoptera, much like that of the $Z$ from birds (Nanda et al. 2008) or the $\mathrm{X}$ from mammals (Ohno 1973; Rat Genome Sequencing Project Consortium 2004).

Table 1 shows a list of B. mori $\mathrm{Z}$ chromosomal genes and the presence of their orthologues in $\mathrm{Z}$ chromosomes of other Lepidoptera. Conserved synteny was detected of genes from position $0.5 \mathrm{Mbp}$ to position 21.8 Mbp of the 22.4 Mbp of the $\mathrm{Z}$ chromosomal DNA sequence. Thus, conserved synteny was found in practically all regions of the $B$. mori $\mathrm{Z}$ chromosome, indicating that the whole $\mathrm{Z}$ chromosome is likely to be conserved. A few exceptions from the synteny rule have been found Bicyclus anynana and Ostrinia nubilalis (Beldade et al. 2009; Kroemer et al. 2011). The exceptions were corroborated by a search in the $B$. mori sequence database. One gene, peptidylprolyl isomerase, from the B. mori $\mathrm{Z}$ chromosome has an orthologue on $B$. anynana chromosome 4 , but not on the $\mathrm{Z}$. Orthologs of two other B. mori Z-linked genes, ribosomal protein L36 (RpL36) and a gene similar to Aedes aegypti suppressin (BGIBMGA002019), are autosomal in O. nubilalis. And one gene (MOF) from B. mori chromosome 17 has an
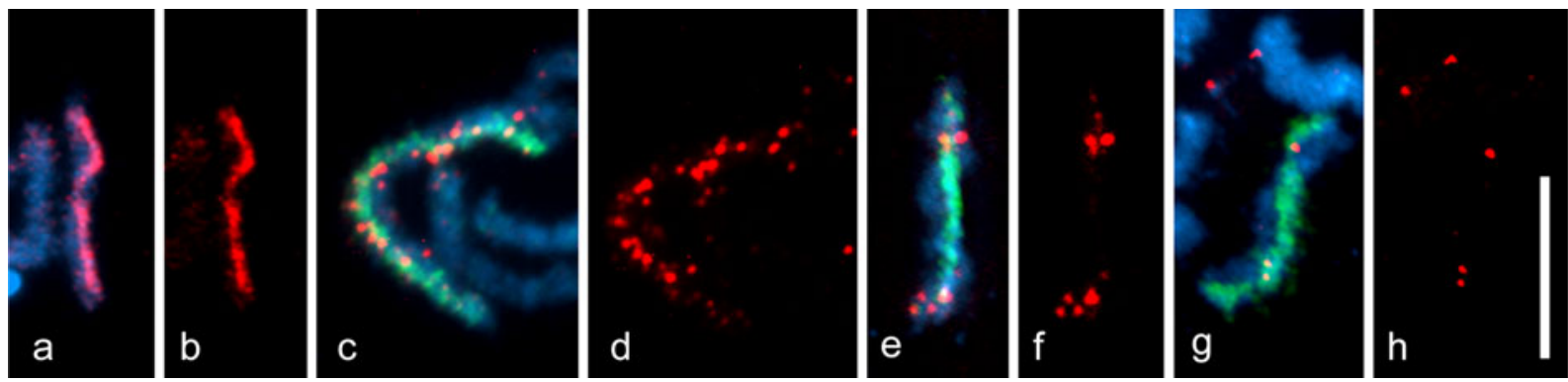

Fig. 5 Zoo-FISH showing the decreasing similarity of the DNA content of the W chromosome among the related species $E$. kuehniella (a, b), C. cautella (c, d), P. interpunctella (e, f) and G. mellonella $(\mathbf{g}, \mathbf{h})$. The pachytene chromosome preparations were probed with a whole W probe from E. kuehniella (red signals). Subsequent hybridisation with species-specific W chromosome painting probes (green signals) identified the $\mathrm{W}$ chromosomes of the respective species (c, e, g) (from Vítková et al. 2007, by courtesy of the authors and with kind permission from Springer Science + Business Media). Bar, $10 \mu \mathrm{m}$ 
Table 1 Conserved synteny of Z-linked genes from B. mori

\begin{tabular}{|c|c|c|c|c|c|c|c|c|c|}
\hline \multicolumn{3}{|c|}{ Bombyx mori } & \multirow{2}{*}{$\begin{array}{l}\text { Manduca } \\
\text { sexta }\end{array}$} & \multirow{2}{*}{$\begin{array}{l}\text { Agrius } \\
\text { convolvuli }\end{array}$} & \multirow{2}{*}{$\begin{array}{l}\text { Samia } \\
\text { cynthia }\end{array}$} & \multirow{2}{*}{$\begin{array}{l}\text { Ostrinia } \\
\text { nubilalis }\end{array}$} & \multirow{2}{*}{$\begin{array}{l}\text { Plutella } \\
\text { xylostella }\end{array}$} & \multirow{2}{*}{$\begin{array}{l}\text { Bicyclus } \\
\text { anynana }\end{array}$} & \multirow{2}{*}{$\begin{array}{l}\text { Heliconius } \\
\text { melpomene }\end{array}$} \\
\hline Gene & Gene Model & Position & & & & & & & \\
\hline & BGIBMGA002079 & 0.5 & + & + & & & & & \\
\hline & BGIBMGA002085 & 1.0 & & & & & & + & \\
\hline & BGIBMGA002034 & 1.6 & & & & & + & & \\
\hline \multirow[t]{5}{*}{$a p$} & BGIBMGA002127 & 3.5 & & & & & & & + \\
\hline & BGIBMGA002140 & 4.1 & & & & & + & & \\
\hline & BGIBMGA000602 & 5.8 & + & + & & & & & \\
\hline & BGIBMGA000612 & 6.0 & & & & + & & & \\
\hline & BGIBMGA000613 & 6.0 & & & & + & & & \\
\hline kettin & BGIBMGA000622 & 6.5 & & & + & + & & & \\
\hline \multirow[t]{2}{*}{ titin2 } & BGIBMGA000624 & 6.6 & + & & & & & & \\
\hline & BGIBMGA000654 & 8.7 & & & & & + & & \\
\hline$T p i$ & BGIBMGA000559 & 9.0 & & & & + & & + & + \\
\hline$Y b p$ & BGIBMGA000526 & 10.9 & & & + & & & & \\
\hline \multirow[t]{4}{*}{ Cat } & BGIBMGA000701 & 10.9 & & & & + & & + & \\
\hline & BGIBMGA000520 & 11.3 & & & & + & & & \\
\hline & BGIBMGA000516 & 11.4 & & & + & & & & \\
\hline & BGIBMGA000517 & 11.4 & & & & & + & & \\
\hline \multirow[t]{4}{*}{ Ftz-fl } & BGIBMGA000716 & 11.7 & & & & + & & & \\
\hline & BGIBMGA000724 & 12.2 & + & + & & & & & \\
\hline & BGIBMGA000743 & 13.4 & & & & & + & & \\
\hline & BGIBMGA000477 & 13.6 & & & & & + & & \\
\hline \multirow[t]{3}{*}{$L d h$} & BGIBMGA012336 & 17.3 & & & & + & & & \\
\hline & BGIBMGA012251 & 17.5 & & & & & + & & \\
\hline & BGIBMGA012356 & 19.2 & + & + & & & & & \\
\hline \multirow[t]{3}{*}{$S h k r$} & BGIBMGA003851 & 20.9 & & & & + & & & \\
\hline & BGIBMGA003892 & 21.5 & & & & + & & & \\
\hline & BGIBMGA003866 & 21.8 & & & & & & + & \\
\hline
\end{tabular}

Bombyx genes are referred to by name and/or gene model (http://sgp.dna.affrc.go.jp/KAIKObase/ and/or http://silkworm.genomics.org. $\mathrm{cn} /$ silkdb/) and Z chromosomal position in Mbp. Their presence in $\mathrm{Z}$ chromosomes of other species is indicated by ' + '. Data are from Yasukochi et al. (2009) (Manduca and Agrius); Yoshido et al. (2011a, b) (Samia); Dopman et al. (2005), Kroemer et al. (2011) and Yasukochi et al. (2011) (Ostrinia); Baxter et al. (2011) (Plutella); Van’t Hof et al. (2008) and Beldade et al. (2009) (Bicyclus) and Jiggins et al. (2005) (Heliconius). Ostrinia, Plutella and Bicyclus are only those genes that were confirmed as orthologues by a new search in the $B$. mori genome

orthologue on the B. anynana $\mathrm{Z}$ chromosome. Thus, at least some transpositions or translocations have occurred during evolution of the $\mathrm{Z}$.

$\mathrm{Z}$ chromosomes appear to play a major role in the speciation process (Sperling 1994; Dopman et al. 2005). Obvious players in the field of reproductive barriers are genes controlling pheromones, pheromone recognition and voltinism. The $\mathrm{Z}$ chromosomes contain many of them, more than expected on the basis of random distribution. A recently discovered example is the tandem array of olfactory receptor genes in the $\mathrm{Z}$ chromosome of O. nubilalis (Yasukochi et al. 2011). Genes on $Z$ chromosomes are subject to the so-called Faster-Z effect (Mank et al. 2010): They are thought to evolve faster than those on autosomes as they are present in a hemizygous state half of the time, and therefore, more exposed to selection forces.

There is another group of sex-related genes in which the content of the $\mathrm{Z}$ differs significantly from that of autosomes in B. mori. For unknown reasons, the $\mathrm{Z}$ 
chromosome carries an overproportionate number of genes solely expressed in the testis (Arunkumar et al. 2009; Walters and Hardcastle 2011).

\section{Dosage compensation}

The dosage of X-and Z-linked genes in one sex is twice that in the other sex. This may pose problems for appropriate expression levels. Species with an XX/XY sex chromosome system, such as mammals, Caenorhabditis and Drosophila, deal with this problem by using chromosome-wide dosage compensation mechanisms (for review, see Chow and Heard 2010). Birds, which are WZ/ZZ species like Lepidoptera, do not possess a chromosome-wide dosage compensation, but genes in a male hypermethylated region are dosage-compensated while the rest are not (Melamed and Arnold 2007). In Lepidoptera, the transcription levels of several genes from Bombyx, Heliconius and Antheraea have been assayed and shown to have an approximate ratio of 1:2 in the same tissues of females and males, respectively (Johnson and Turner 1979; Gotter et al. 1999; Suzuki et al. 1999). The results were confirmed in most genes of a wider, microarray-based investigation of transcription levels of 579 Z-linked genes in B. mori: Hence, it appears that Lepidoptera do not have a chromosome-wide dosage compensation mechanism (Zha et al. 2009). In a new microarray study, Walters and Hardcastle (2011) found a 1:1 ratio of $\mathrm{Z}$ chromosomal transcript levels between females and males relative to autosomal gene expression. From these data, it seems that there is dosage compensation in B. mori. The question is not settled though, as the problem of normalising the microarray data appears to be the cause for the different interpretations.

\section{Exploiting and manipulating lepidopteran sex chromosomes for economic purposes}

Several moth species are economically important, either as useful or harmful insects. The domesticated silkmoth, B. mori, and a few wild species are commercially important as producers of silk. Many other moth species are agricultural pests or infest stored goods.
Fig. 6 Scheme of genetic sexing proposed by Strunnikov (1975). Males carrying Z-linked recessive trans-heterozygous lethal mutations (sl-1 and $s l-2)$ are crossed with wild-type females. All-female progeny are lethal because they inherit either $s l-1$ or $s l-2$ from the father. Male progeny survive because of the wild-type alleles inherited from the mother

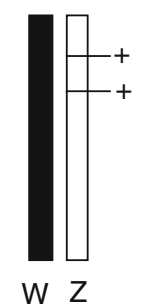

Normal female

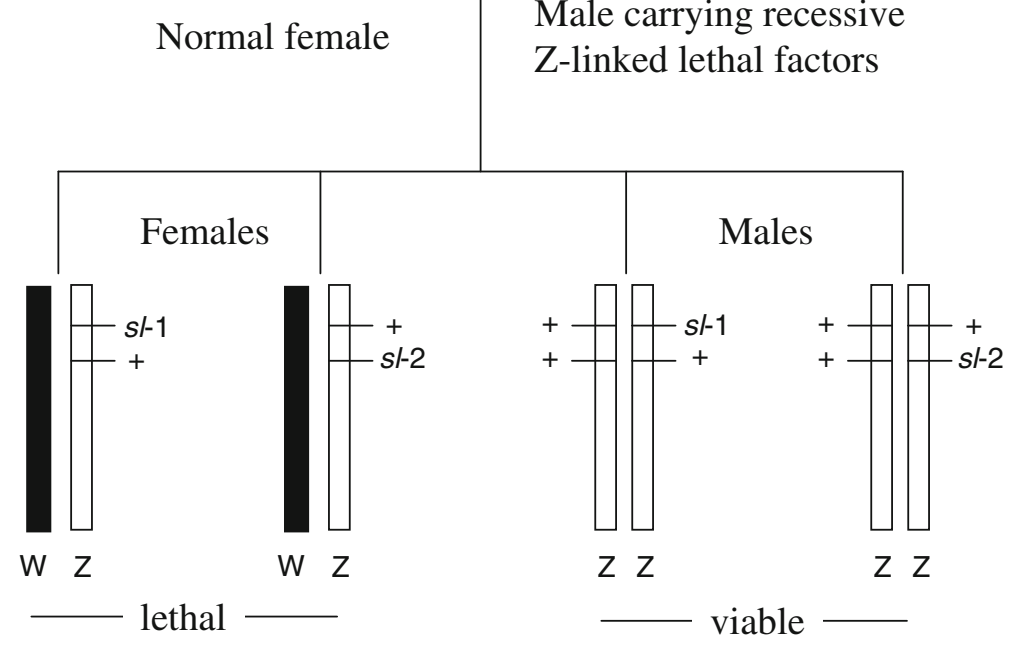


In B. mori, males are the preferred sex for commercial applications. Males produce approximately $20 \%$ more silk and have a shorter and more homogeneous feeding period. It has been a long-standing wish to discriminate between females and males as early as possible to reduce costs and increase silk production. So-called sexing strains have been developed, therefore, by translocation of autosomal segments carrying genes for visible traits to the $\mathrm{W}$ chromosome (Tazima 1964; Nagaraju et al. 1996). The sexes can be distinguished in one of these as early as at the egg stage by colour. Strunnikov (1975) went further and proposed a scheme in which live female offspring do not survive. According to this scheme, males with two balanced nonallelic recessive Z-linked lethal factors are crossed to normal females. The resulting progeny consist only of males, since all-female progeny are lethal due to the hemizygous lethal allele inherited from the father (Fig. 6). 'Platina Boy' is a male-only commercial B. mori product in Japan, based on Strunnikov's proposal (Ohnuma 2006).

Strunnikov's proposal has also been put into reality in a storage pest, the meal moth E. kuehniella (Marec et al. 1999). Trans-heterozygous males carrying two balanced lethals released in sufficient numbers in an infesting population reduced the proportion of females in the succeeding generations.

New schemes are presently introduced into the sterile insect technique for pest control, making use of genetically manipulated insects (Alphey et al. 2002), some of them already in the test phase. Manipulating the $\mathrm{W}$ chromosome by introduction of a conditional lethal transgene is a proposal which is being pursued in the codling moth, C. pomonella, which infests apples (Marec et al. 2007).

\section{Outlook}

The introduction of massively parallel sequencing techniques, so-called next gen sequencing, has revolutionised research in many fields of genetics. The results are not yet fully realised in the fields discussed here. But in view of the many whole-genome sequencing projects presently under way and the intended accessibility of sequence data, it is easy to predict that in the near future, all topics of this review will gain massively from those data. Primary sex-determining signals, the sex-determining cascade and the composition of chromosomes including sex chromosomes, evolution of chromosomes and conserved synteny all can easily be studied on the sequence level. That will not make cytogenetics obsolete; rather, it will be important for it to persist and improve as a critical framework for organising and extending molecular data.

Acknowledgements We appreciate Magda Vítková's (České Budějovice) kind supply of figures. The useful comments and suggestions from the anonymous reviewers are gratefully acknowledged. We thank Yasuhiro Yamada (Sapporo, Japan) for long-term technical assistance. K.S. received a Grants-in-Aid for Scientific Research (23380030) from Japan Society for the Promotion of Science.

\section{References}

Abe H, Fujii T, Shimada T (2010) Sex chromosomes and sex determination in Bombyx mori. In: Goldsmith MR, Marec $\mathrm{F}$ (eds) Molecular biology and genetics of the Lepidoptera. CRC, Boca Raton, pp 65-87

Alphey L, Beard CB, Billingsley P, Coetzee M, Crisanti A, Curtis C, Eggleston P, Godfray C, Hemingway J, JacobsLorena M, James AA, Kafatos FC, Mukwaya LG, Paton M, Powell JR, Schneider W, Scott TW, Sina B, Sinden R, Sinkins S, Spielman A, Touré Y, Collins FH (2002) Malaria control with genetically manipulated insect vectors. Science 298:119-121

Arunkumar KP, Mita K, Nagaraju J (2009) The silkworm Z chromosome is enriched in testis-specific genes. Genetics 182:493-501

Baxter SW, Davey JW, Johnston JS, Shelton AM, Heckel DG, Jiggins CD, Blaxter ML (2011) Linkage mapping and comparative genomics using next-generation $\mathrm{RAD}$ sequencing of a non-model organism. PLoS One 6:e19315

Beldade P, Saenko SV, Pul N, Long AD (2009) A gene-based linkage map for Bicyclus anynana butterflies allows for a comprehensive analysis of synteny with the lepidopteran reference genome. PLoS Genet 5:e1000366

Charlesworth D, Charlesworth B, Marais G (2005) Steps in the evolution of heteromorphic sex chromosomes. Heredity 95:118-128

Chow JC, Heard E (2010) Nuclear organization and dosage compensation. Cold Spring Harb Perspect Biol 2:a000604

Dopman EB, Pérez L, Bogdanowicz SM, Harrison RG (2005) Consequences of reproductive barriers for genealogical discordance in the European corn borer. Proc Natl Acad Sci USA 102:14706-14711

Franco MG, Rubini PG, Vecchi M (1982) Sex determinants and their distribution in various populations of Musca domestica L. of Western Europe. Genet Res 40:279-293

Fuková I, Traut W, Vitková M, Nguyen P, Kubíčková S, Marec F (2007) Probing the W chromosome of the codling moth, Cydia pomonella, with sequences from microdissected sex chromatin. Chromosoma 116:135-145 
Gotter AL, Levine JD, Reppert SM (1999) Sex-linked period genes in the silkmoth, Antheraea pernyi: implications for circadian clock regulation and the evolution of sex chromosomes. Neuron 24:953-965

Grimaldi DA, Engel MS (2005) Evolution of the insects. Cambridge University Press, New York

Henking H (1891) Untersuchungen über die ersten Entwicklungsvorgänge in den Eiern der Insekten. Über Spermatogenese und deren Beziehung zur Entwicklung bei Pyrrhocoris apterus L. Z Wiss Zool 51:685-736

Jiggins CD, Mavarez J, Beltrán M, McMillan WO, Johnston JS, Bermingham E (2005) A genetic linkage map of the mimetic butterfly Heliconius melpomene. Genetics 171:557-570

Johnson MS, Turner JRG (1979) Absence of dosage compensation for a sex-linked enzyme in butterflies (Heliconius). Heredity 43:71-77

Kato Y, Kobayashi K, Watanabe H, Iguchi T (2011) Environmental sex determination in the branchiopod crustacean Daphnia magna: deep conservation of a Doublesex gene in the sex-determining pathway. PLoS Genet 7:e1001345

Kristensen NP, Skalski AW (1999) Phylogeny and palaeontology. In: Kristensen NP (ed) Handbuch der Zoologie, a natural history of the phyla of the animal kingdom. Vol. IV, Arthropoda: Insecta, part 35, Lepidoptera, moths and butterflies, Vol. 1: evolution, systematics and biogeography, vol IV. Walter de Gruyter, Berlin, pp 7-25

Kristensen NP, Scoble MJ, Karsholt O (2007) Lepidoptera phylogeny and systematics: the state of inventorying moth and butterfly diversity. Zootaxa 1668:699-747

Kroemer JA, Coates BS, Nusawardani T, Rider SD Jr, Fraser LM, Hellmich RL (2011) A rearrangement of the Z chromosome topology influences the sex-linked gene display in the European corn borer, Ostrinia nubilalis. Mol Genet Genomics 286:37-56

Lukhtanov VA (2000) Sex chromatin and sex chromosome systems in non-ditrysian Lepidoptera (Insecta). J Zool Syst Evol Res 38:73-79

Mank JE, Vicoso B, Berlin S, Charlesworth B (2010) Effective population size and the Faster-X effect: empirical results and their interpretation. Evolution 64:663-674

Marec F, Novák K (1998) Absence of sex chromatin corresponds with a sex-chromosome univalent in females of Trichoptera. Eur J Entomol 95:197-209

Marec F, Kollárová I, Pavelka J (1999) Radiation-induced inherited sterility combined with a genetic sexing system in Ephestia kuehniella (Lepidoptera: Pyralidae). Ann Entomol Soc Am 92:250-259

Marec F, Tothová A, Sahara K, Traut W (2001) Meiotic pairing of sex chromosome fragments and its relation to atypical transmission of a sex-linked marker in Ephestia kuehniella (Insecta, Lepidoptera). Heredity 87:659-671

Marec F, Neven LG, Fuková I (2007) Developing transgenic sexing strains for the release of nontransgenic sterile male codling moths Cydia pomonella. In: Vreysen MJB, Robinson AS, Hendrichs J (eds) Area-wide control of insect pests: from research to field implementation. Springer, Dordrecht, pp 103-111

Marec F, Sahara K, Traut W (2010) Rise and fall of the W chromosome in Lepidoptera. In: Goldsmith MR, Marec F (eds) Molecular biology and genetics of the Lepidoptera. CRC, Boca Raton, pp 49-63
Melamed E, Arnold AP (2007) Regional differences in dosage compensation on the chicken $\mathrm{Z}$ chromosome. Genome Biol 8(9):R202

Nagaraju J, Raje U, Datta RK (1996) Crossbreeding and heterosis in the silkworm, Bombyx mori, a review. Sericologia 36:1-20

Nanda I, Schlegelmilch K, Haaf T, Schartl M, Schmid M (2008) Synteny conservation of the $Z$ chromosome in 14 avian species (11 families) supports a role for $Z$ dosage in avian sex determination. Cytogenet Genome Res 122:150-156

Niimi T, Sahara K, Oshima H, Yasukochi Y, Ikeo K, Traut W (2006) Molecular cloning and chromosomal localization of the Bombyx Sex-lethal gene. Genome 49:263-268

Ohno S (1973) Ancient linkage groups and frozen accidents. Nature 244:259-262

Ohnuma A (2006) The history of the development of malerearing silkworm strain, Bombyx mori. Rep J Dainippon Silk Found 54:1-10 [in Japanese]

Rat Genome Sequencing Project Consortium (2004) Genome sequence of the Brown Norway rat yields insights into mammalian evolution. Nature 2004(428):493-521.

Rathjens B (1974) Zur Funktion des W-Chromatins bei Ephestia kuehniella (Lepidoptera). Isolierung und Charakterisierung von W-Chromatin-Mutanten. Chromosoma 47:21-44

Robinson R (1971) Lepidoptera genetics. Pergamon, Oxford

Sahara K, Marec F, Eickhoff U, Traut W (2003a) Moth sex chromatin probed by comparative genomic hybridization (CGH). Genome 46:339-342

Sahara K, Yoshido A, Kawamura N, Ohnuma A, Abe H, Mita K, Oshiki T, Shimada T, Asano S, Bando H, Yasukochi Y (2003b) W-derived BAC probes as a new tool for identification of the $\mathrm{W}$ chromosome and its aberrations in Bombyx mori. Chromosoma 112:48-55

Smith CA, Roeszler KN, Ohnesorg T, Cummins DM, Farlie PG, Doran TJ, Sinclair AH (2009) The avian Z-linked gene $D M R T 1$ is required for male sex determination in the chicken. Nature 461:267-271

Sperling FAH (1994) Sex-linked genes and species differences in Lepidoptera. Can Entomol 126:807-818

Strunnikov VA (1975) Sex control in silkworms. Nature 255:111-113

Suzuki MG (2010) Sex determination: insights from the silkworm. J Genet 89:357-363

Suzuki MG, Shimada T, Kobayashi M (1999) Bm kettin, homologue of the Drosophila kettin gene, is located on the $\mathrm{Z}$ chromosome in Bombyx mori and is not dosage compensated. Heredity $82: 170-179$

Suzuki MG, Imanishi S, Dohmae N, Asanuma M, Matsumoto S (2010) Identification of a male-specific RNA binding protein that regulates sex-specific splicing of Bmdsx by increasing RNA binding activity of BmPSI. Mol Cell Biol 30:5776-5786

Tazima Y (1964) The genetics of the silkworm. Academic, London

The International Silkworm Genome Consortium (2008) The genome of a lepidopteran model insect, the silkworm Bombyx mori. Insect Biochem Mol Biol 38:1036-1045

Traut W (2010) New Y chromosomes and early stages of sex chromosome differentiation: sex determination in Megaselia. J Genet 89:307-313

Traut W, Marec F (1996) Sex chromatin in Lepidoptera. Q Rev Biol 71:239-256 
Traut W, Marec F (1997) Sex chromosome differentiation in some species of Lepidoptera (Insecta). Chromosome Res $5: 283-291$

Traut W, Rathjens B (1973) Das W-Chromosom von Ephestia kuehniella (Lepidoptera) und die Ableitung des Geschlechtschromatins. Chromosoma 41:437-446

Traut W, Weith A, Traut G (1986) Structural mutants of the W chromosome in Ephestia (Insecta, Lepidoptera). Genetica 70:69-79

Traut W, Sahara K, Otto TD, Marec F (1999) Molecular differentiation of sex chromosomes probed by comparative genomic hybridization. Chromosoma 108:173-180

Traut W, Sahara K, Marec F (2007) Sex chromosomes and sex determination in Lepidoptera. Sexual Dev 1:332-346

Van't Hof AE, Marec F, Saccheri IJ, Brakefield PM, Zwaan BJ (2008) Cytogenetic characterization and AFLP-based genetic linkage mapping for the butterfly Bicyclus anynana, covering all 28 karyotyped chromosomes. PLoS One 3: e3882

Vítková M, Fuková I, Kubíčková S, Marec F (2007) Molecular divergence of the $\mathrm{W}$ chromosomes in pyralid moths (Lepidoptera). Chromosome Res 15:917-930

Walters JR, Hardcastle TJ (2011) Getting a full dose? Reconsidering sex chromosome dosage compensation in the silkworm, Bombyx mori. Genome Biol Evol 3:491-504

Wolf KW (1996) The structure of condensed chromosomes in mitosis and meiosis of insects. Int $\mathrm{J}$ Insect Morphol Embryol 25:37-62
Yasukochi Y, Tanaka-Okuyama M, Shibata F, Yoshido A, Marec F, Wu C, Zhang H, Goldsmith MR, Sahara K (2009) Extensive conserved synteny of genes between the karyotypes of Manduca sexta and Bombyx mori revealed by BAC-FISH mapping. PLoS One 4:e7465

Yasukochi Y, Miura N, Nakano R, Sahara K, Ishikawa Y (2011) Sex-linked pheromone receptor genes of the European corn borer, Ostrinia nubilalis, are in tandem arrays. PLoS One 6:e18843

Yoshido A, Marec F, Sahara K (2005) Resolution of sex chromosome constitution by genomic in situ hybridization and fluorescence in situ hybridization with (TTAGG) $n$ telomeric probe in some species of Lepidoptera. Chromosoma 114:193-202

Yoshido A, Yamada Y, Sahara K (2006) The W chromosome detection in several lepidopteran species by genomic in situ hybridization (GISH). J Insect Biotech Seric 75:147-151

Yoshido A, Sahara K, Marec F, Matsuda Y (2011a) Step-by-step evolution of neo-sex chromosomes in geographical populations of wild silkmoths, Samia cynthia ssp. Heredity 106:614-624

Yoshido A, Yasukochi Y, Sahara K (2011b) Samia cynthia versus Bombyx mori: comparative gene mapping between a species with a low-number karyotype and the model species of Lepidoptera. Insect Biochem Mol Biol 41:370-377

Zha X, Xia Q, Duan J, Wang C, He N, Xiang Z (2009) Dosage analysis of $\mathrm{Z}$ chromosome genes using microarray in silkworm, Bombyx mori. Insect Biochem Mol Biol 39:315321 